\title{
Corporate real estate strategy: the Malaysian perspective
}

\begin{abstract}
This study analyses the relationships between corporate real estate (CRE) strategy and financial performance of companies in Malaysia during 1998 and 2003. The identification of CRE strategies is based on the work of Nourse and Roulac (1993) and maps these strategies to the financial performance of companies through multivariate models. The results indicate that $80 \%$ of the companies had a dominant CRE strategy that matched the Nourse and Roulac framework in both periods. For the 1998 analysis, there was no apparent link between CRE strategy and share performance. Indeed those companies not having a strategy had better share performance. In contrast, there was evidence of a CRE strategy making a contribution to share price in 2003. In particular, the strategy to facilitate managerial process and knowledge framework is shown to enhance financial performance, compared to other CRE strategies or the no strategy alternative. This study concludes that CRE strategy can make a positive contribution to financial performance, but needs more attention from management in order to maximize its potential.
\end{abstract}

